\title{
Stimulants associated with reduced risk of hospitalization for motor vehicle accident injury in patients with obstructive sleep apnea-a nationwide cohort study
}

Yi-Chang Lin ${ }^{1,2}$, Tien-Yu Chen ${ }^{3,4}$, Wu-Chien Chien ${ }^{5,6,7}$, Chi-Hsiang Chung ${ }^{5,6,8}$, Hsin-An Chang ${ }^{3,9}$, Yu-Chen Kao ${ }^{3,10}$, Chien-Sung Tsai ${ }^{1}$, Chih-Sheng Lin ${ }^{2^{*}+}$ and Nian-Shen Tzeng ${ }^{3,9^{*+}}$ (D)

\begin{abstract}
Background: The risk of injury directly related to hospitalization for motor vehicle accidents (MVAs) in the obstructive sleep apnea (OSA) patients has not been thoroughly understood. Our study aimed to examine the association between the OSA and the hospitalization for an MVA injury.

Methods: This retrospective cohort study used Taiwan's National Health Insurance Research Database (NHIRD) between 2000 and 2015. The OSA patients aged $\geq 20$ years by age, sex, and index-year matched by non-OSA controls were enrolled (1:3). We used the Cox proportional regression model to evaluate the association between the OSA and the hospitalization for an MVA injury.

Results: The incidence rate of hospitalization for an MVA injury was higher in the OSA cohort $(N=3025)$ when compared with the non-OSA controls ( $N=9075)$, as 575.3 and 372.0 per 100,000 person-years, respectively $(p<$ 0.001). The Kaplan-Meier analysis showed that the OSA cohort had a significantly higher incidence of hospitalization for the MVA injury (log-rank test, $p<0.001$ ). After adjusting for the covariates, the risk of hospitalization for the MVA injury among the OSA was significantly higher (hazard ratio $[\mathrm{HR}]=2.18$; $95 \%$ confidence interval $[\mathrm{Cl}]=1.79-2.64 ; p<$ 0.001 ). Stimulants usage was associated with a nearly $20 \%$ decrease in the risk of an overall hospitalization for an MVA injury in the OSA patients.

Conclusions: This study provides evidence that patients with OSA are at a two-fold higher risk of developing hospitalization for an MVA injury, and the usage of modafinil and methylphenidate was associated with a lower risk of an overall hospitalization for the MVA injury.
\end{abstract}

Keywords: Obstructive sleep apnea, Motor vehicle accident injury, Cohort study, National Health Insurance Research Database, Longitudinal health insurance database

\footnotetext{
*Correspondence: lincs@mail.nctu.edu.tw; pierrens@mail.ndmctsgh.edu.tw

${ }^{\dagger}$ Chih-Sheng Lin and Nian-Shen Tzeng contributed equally to this work.

2Department of Biological Science and Technology, National Chiao Tung University, No.75, Po-Ai Street, Hsinchu 30068, Taiwan

${ }^{3}$ Department of Psychiatry, Tri-Service General Hospital, School of Medicine,

National Defense Medical Center, No. 325, Section 2, Cheng-Kung Road,

Neihu District, Taipei City 11490, Taiwan

Full list of author information is available at the end of the article
}

(c) The Author(s). 2020 Open Access This article is distributed under the terms of the Creative Commons Attribution 4.0 International License (http://creativecommons.org/licenses/by/4.0/), which permits unrestricted use, distribution, and reproduction in any medium, provided you give appropriate credit to the original author(s) and the source, provide a link to the Creative Commons license, and indicate if changes were made. The Creative Commons Public Domain Dedication waiver (http://creativecommons.org/publicdomain/zero/1.0/) applies to the data made available in this article, unless otherwise stated. 


\section{Background}

Obstructive sleep apnea (OSA) is a common disorder characterized by repeated partial, or the complete collapse of, the upper airway with episodes of apnea and hypopnea during sleep [1]. OSA affects 3-7\% adults in general adults and up to $9-15 \%$ of middle-aged adults. According to the varying criteria of diagnostic studies, with a male predominance [2, 3]. Excessive daytime sleepiness (EDS) and cognitive performance from OSA are associated with occupational injury and hospitalization for motor vehicle accidents (MVAs) [4].

An MVA injury is a major global public health problem, which has accounted for mortality, morbidity and economic loss [5, 6]. Sleep disorders have been related to MVAs in previous researches $[7,8]$. One study also found that problems such as sleepiness would increase the risk of near-miss accidents [9], and another study showed that drivers with sleep-related near misses may predict MVAs [8]. The OSA patients have a higher risk of falling asleep while driving and are 3-fold more likely to cause MVA injuries [10,11], thus, hypersomnolence related to OSA was associated with a high risk when driving [7]. Previous studies have also shown that treating OSA, for example, with continuous positive airway pressure (CPAP) could reduce the risk of an MVA, costs, and fatalities related to these MVAs $[10,12]$.

One cross-sectional study has found that OSA, sleep debt, and EDS are independently associated with road accidents in truck drivers [13]. Another study has shown that about $7 \%$ of road traffic accident injuries for the male drivers involved in MVAs are attributable to the OSAS [14]. A Swedish study has shown that the CPAP use $\geq 4 \mathrm{~h} /$ night was associated with a reduction of an MVA incidence [15]. However, no previous cohort study has been conducted to examine the association between OSA and the risk of injury related to hospitalization for MVAs. Therefore, a study is needed to estimate the risk of hospitalization for an MVA injury in patients with OSA in Taiwan. This is an exploratory study to investigate as towhether OSA and the usage of modafinil and methylphenidate, CPAP, and pharyngeal surgery were associated with the risk of hospitalization for an MVA injury. We thereby conducted this cohort study, using Taiwan's nationwide database (the National Health Insurance Research Database [NHIRD]), to examine as to whether the OSA has been associated with the risk of hospitalization for an MVA injury, and the association between the usage of stimulants, CPAP, or pharyngeal surgery, and the risk of hospitalization for an MVA injury in the OSA patients.

\section{Methods}

\section{Data sources}

The National Health Insurance (NHI) Program was launched in Taiwan in 1995, and as of June 2009, included contracts with $97 \%$ of the medical providers with approximately 23 million beneficiaries, or more than $99 \%$ of the entire population $[16,17]$. The NHIRD, which contains all the claims data of the beneficiaries, uses the International Classification of Diseases, 9th Revision, Clinical Modification (ICD-9-CM) codes to record the diagnoses [18]. The details of the program have been documented in previous studies [19-24].

A subset of the NHIRD, the Longitudinal Health Insurance Database (LHID) of one million randomized sampled population between 2000 and 2015, was used to study the association between OSA and the risk of hospitalization for MVA injury. The present study used the NHIRD to identify patients aged $\geqq 20$ with a diagnosis of OSA, based on the ICD-9-CM codes, 327.23, 780.51, 780.53, and 780.57. Patients with narcolepsy, ICD-9-CM code 347, were excluded. In Taiwan, the OSA diagnostic criteria is according to the Report of an American Academy of Sleep Medicine Task Force published in 1999, that is, the presence of sleep disordered breathing measured in an overnight sleep study combined with the presence of symptoms typical of the disorder, most notably excessive daytime sleepiness [25], during all the study period. Each enrolled patient in the OSA cohort was required to have received the procedure codes of polysomnography (PSG) within 1 year before or after the OSA code occurred, during 2000-2015. In one recent study, the accuracy of diagnosis of the OSA recorded in the NHIRD, has been validated as 99\% [26].

\section{Study design and sampled participants}

This study was of a population-based, matched-cohort design. Patients aged $\geqq 20$ with newly diagnosed OSA were selected from the LHID between January 1, 2000, and December 31, 2015. The patients with OSA before 2000 were excluded. In addition, the patients diagnosed with an injury related to MVAs, (ICD-9-CM codes: E810-E819) plus injuries codes (ICD-9-CM codes: 800.xx- 999.xx), before 2000, or before the first visit for OSA were also excluded (Additional file 1: Figure S1).

\section{Covariates}

The covariates included sex, age groups (20-44, 45-64, and $\geqq 65$ years), geographical area of residence (north, center, south, and east of Taiwan), urbanization level of residence (levels 1 to 4), and monthly insured premiums (in New Taiwan Dollars [NT\$]; <18,000, 18,000-34,999, $\geq 35,000$ ). A health insurance premium is an upfront payment made on behalf of an individual or family in order to keep their health insurance policy active, and the insured premiums for the NHI are based on the salary of the insured individuals, and calculated according to the NHI policy [27]. The urbanization level of residence was defined according to the population and various indicators 
of the level of development. Level 1 was defined as a population of $>1,250,000$, and a specific designation as political, economic, cultural, and metropolitan development. Level 2 was defined as a population between 500 , 000 and 1,249,999, and as playing an important role in the politics, economy, and culture. Urbanization levels 3 and 4 were defined as a population between 149,999 and 499, 999 , and < 149,999, respectively.

Usage of psychostimulants, including modafinil or methylphenidate, and records of procedures of tonsillectomy, adenoidectomy, adenotonsillectomy, and vulopalatopharyngoplasty, were collected. The proportion of days covered (PDC) by medications within the entire follow-up period was divided into two categories $(1-50 \%, 51-100 \%)$ to compare the levels of adherence to the drug regimens by the patients, and to correlate the adherence level with the incidence of hospitalization for MVA injury. The CPAP is not reimbursed in the NHI policy, therefore, we collected this record with the reference of one previous research. Briefly, among the patients diagnosed with OSA who used CPAP, an additional PSG would be performed within the first 6 months of the OSA diagnosis, for the titration of the CPAP. Therefore, we used the additional PSG records 6 months after the OSA diagnosis to define the cases that used CPAP [28].

The usage of hypnotic (Z-drugs and benzodiazepines), and other sedative medications such as antihistamines, antidepressants, and antipsychotics commonly used in Taiwan [29], were also analyzed as the covariates. The data of the defined daily dose (DDD) were obtained from the WHO Collaborating Centre for Drug Statistics Methodology (https://www.whocc. no/), and the duration of the usage of hypnotics, antidepressants, antipsychotics, and antihistamines was calculated by dividing the cumulative doses by the DDD of these medications.

\section{Comorbidity}

Comorbidities were assessed using the Charlson Comorbidity Index (CCI), which categorizes the comorbidities using the ICD-9-CM codes, scores each comorbidity category, and combines all the scores to calculate a single comorbidity score, with different weights (Additional file 2: Table S1). A score of zero indicates that no comorbidities were found, and higher scores indicate higher comorbidity burdens [30-32]. The comorbidities including insomnia (ICD-9CM codes: 307.4, 780.5 except 780.51, 780.53, 780.57), idiopathic hypersomnia (ICD-9-CM: 327.11, 327.12), circadian rhythm sleep disorder, shift work type (ICD9-CM Code: 327.36), restless leg syndrome (RLS, ICD9-CM code: 333.94), periodic leg movements disorder (PLMD; ICD-9-CM code: 327.51), anxiety disorders (ICD-9-CM codes: 300.x), depressive disorders (ICD-9CM codes: $296.2 x-296.3 x, 300.4,311)$, bipolar disorders (ICD-9-CM codes: 296.0, 296.4x-296.8x), psychotic disorders (ICD-9-CM codes: 295.xx, 297-298), alcoholrelated disorders (ICD-9-CM codes: 303.x, 305.0x, V11.3; 291.x), and other substance-related disorders (ICD-9-CM codes: 304.0x, 304.1x, 304.2x, 304.3x, 304.5x, 304.6x, 304.7x, 304.8x, 304.9x, 305.0x, 305.1x, 305.2x, 305.3x, 305.4x, 305.5x, 305.6x, 305.8x, 305.9x, and 292.x) were also assessed in this study.

\section{Major outcomes}

All of the study participants were followed from the index date until the suffering of hospitalization for an MVA injury (ICD-9-CM codes: E810-E819) plus injuries codes (ICD-9-CM codes: 800.xx- 999.xx, withdrawal from the NHI program, or the end of 2015. During this study, there were $6.17 \%$ participants missing from the study participants by withdrawal from the NHI program. The severity of injury was also analyzed in this study, and was classified as the Injury Severity Score (ISS) $<16$ or $\geqq 16$, injury diagnosis, and the types were also recorded, since the ISS is an established medical score to assess the trauma severity, while patients with the ISS $\geqq$ 16 was defined as a major trauma [33].

\section{Statistical analysis}

All statistical analyses were performed using the SPSS for Windows, version 22.0 (IBM Corp., Armonk, NY). $\mathrm{X}^{2}$ and $\mathrm{t}$ tests were used to evaluate the distributions of the categorical and continuous variables, respectively, with a Fischer exact examination. The multivariate Cox proportional hazards regression analysis was used to determine the risk of the hospitalization for an MVA injury, and the results were presented as a hazard ratio (HR) with a 95\% confidence interval (CI). The difference in the risk of hospitalization for an MVA injury, between the OSA cohort and the non-OAS control, was estimated using the Kaplan-Meier method with the log-rank test. A 2-tailed $p$ value $<0.05$ was considered to indicate the statistical significance.

\section{Results \\ Sample characteristics}

Table 1 shows the sex, age, comorbidities, urbanization, area of residence, monthly insured premiums of the OSA patients, and the controls. When compared to the controls, the OSA patients tended to have more insomnia, idiopathic hypersomnia, anxiety disorder, depressive disorder, bipolar disorder, psychotic disorder, alcoholrelated disorders and other substance-related disorders. The OSA patients had higher CCI scores $(\mathrm{CCI}=1.8 \pm 3.1$ [range: $0-24$ ] vs $1.0 \pm 2.0$ [range: $0-22$ ],$p<0.001$ ), and the OSA patients tended to have higher rates of living in the urbanization level 1 area, and in the north and middle of Taiwan, than the control groups. In addition, in the OSA patients, there were $70(0.77 \%)$ individuals with 
Table 1 Characteristics of study at the baseline

\begin{tabular}{|c|c|c|c|c|c|}
\hline \multirow[t]{2}{*}{ Variables } & \multicolumn{2}{|l|}{ OSA } & \multicolumn{2}{|c|}{ No OSA } & \multirow[t]{2}{*}{$P$} \\
\hline & $n$ & $\%$ & $n$ & $\%$ & \\
\hline Total & 3025 & 25.0 & 9075 & 75.0 & \\
\hline \multicolumn{5}{|l|}{ Sex } & 0.999 \\
\hline Male & 2030 & 67.1 & 6090 & 67.1 & \\
\hline Female & 995 & 32.9 & 2985 & 32.9 & \\
\hline Age (years) & \multicolumn{2}{|c|}{$56.1 \pm 18.2$} & \multicolumn{2}{|c|}{$56.0 \pm 18.0$} & 0.662 \\
\hline \multicolumn{5}{|l|}{ Age group (years) } & 0.999 \\
\hline $20-44$ & 755 & 25.0 & 2265 & 25.0 & \\
\hline $45-64$ & 1065 & 35.2 & 3195 & 35.2 & \\
\hline$\geqq 65$ & 1205 & 39.8 & 3615 & 39.8 & \\
\hline Insured premium (NT\$) & \multicolumn{2}{|c|}{$20,124.3 \pm 22,454.2$} & \multicolumn{2}{|c|}{$20,207.1 \pm 22,579.8$} & 0.861 \\
\hline Insured premium group (NT\$) & \multicolumn{4}{|l|}{ a } & 0.910 \\
\hline$<18,000$ & 2564 & 84.8 & 7661 & 84.4 & \\
\hline $18,000-34,999$ & 292 & 9.7 & 897 & 9.9 & \\
\hline$\geqq 35,000$ & 169 & 5.6 & 517 & 5.7 & \\
\hline $\mathrm{CCl}$ & \multicolumn{2}{|c|}{$1.8 \pm 3.1$ (range: $0-24$ ) } & \multicolumn{2}{|c|}{$1.0 \pm 2.0$ (range: $0-22$ ) } & $<0.001$ \\
\hline \multicolumn{6}{|l|}{ Comorbidities } \\
\hline Insomnia & 1875 & 62.0 & 3126 & 34.4 & $<0.001$ \\
\hline Restless leg syndrome & 9 & 0.3 & 25 & 0.3 & 0.843 \\
\hline Idiopathic hypersomnia & 21 & 0.7 & 6 & 0.1 & $<0.001$ \\
\hline Circadian rhythm sleep disorder, shift work type & 2 & 0.1 & 0 & 0.0 & 0.062 \\
\hline Anxiety disorders & 785 & 26.0 & 1024 & 11.3 & $<0.001$ \\
\hline Depressive disorders & 998 & 33.0 & 1186 & 13.1 & $<0.001$ \\
\hline Bipolar disorders & 371 & 12.3 & 690 & 7.6 & $<0.001$ \\
\hline Psychotic disorders & 624 & 20.6 & 834 & 9.2 & $<0.001$ \\
\hline Periodic limb movements disorder & 3 & 0.1 & 8 & 0.1 & 0.862 \\
\hline Alcohol-related disorders & 216 & 7.1 & 485 & 5.3 & $<0.001$ \\
\hline Other substance-related disorders & 397 & 13.1 & 679 & 7.5 & $<0.001$ \\
\hline \multicolumn{6}{|l|}{ Medications } \\
\hline Hypnotics (Z-drugs and benzodiazepine) & 2262 & 74.8 & 1986 & 21.9 & $<0.001$ \\
\hline Antihistamines & 1264 & 41.8 & 3346 & 36.9 & $<0.001$ \\
\hline Antidepressants & 1095 & 36.2 & 2131 & 23.5 & $<0.001$ \\
\hline Antipsychotics & 1176 & 38.9 & 2510 & 27.7 & $<0.001$ \\
\hline \multicolumn{5}{|l|}{ Location } & $<0.001$ \\
\hline Northern Taiwan & 1389 & 45.9 & 3756 & 41.4 & \\
\hline Middle Taiwan & 900 & 29.8 & 2552 & 28.1 & \\
\hline Southern Taiwan & 669 & 22.1 & 2234 & 24.6 & \\
\hline Eastern Taiwan & 66 & 2.2 & 502 & 5.5 & \\
\hline Outlets islands & 1 & 0.03 & 31 & 0.3 & \\
\hline \multicolumn{5}{|l|}{ Urbanization level } & $<0.001$ \\
\hline 1 (The highest) & 1528 & 50.5 & 3130 & 34.5 & \\
\hline 2 & 1057 & 34.9 & 3970 & 43.8 & \\
\hline 3 & 189 & 6.3 & 696 & 7.7 & \\
\hline 4 (The lowest) & 251 & 8.3 & 1279 & 14.1 & \\
\hline
\end{tabular}


Table 1 Characteristics of study at the baseline (Continued)

\begin{tabular}{|c|c|c|c|c|c|}
\hline \multirow[t]{2}{*}{ Variables } & \multicolumn{2}{|l|}{ OSA } & \multicolumn{2}{|c|}{ No OSA } & \multirow[t]{2}{*}{$P$} \\
\hline & $\bar{n}$ & $\%$ & n & $\%$ & \\
\hline Level of care & & & & & $<0.001$ \\
\hline Medical center & 1706 & 56.4 & 3191 & 35.2 & \\
\hline Regional hospital & 910 & 30.1 & 3182 & 35.1 & \\
\hline Local hospital & 409 & 13.5 & 2702 & 29.8 & \\
\hline
\end{tabular}

OSA obstructive sleep apnea, $P$ Chi-square/Fisher exact test on category variables and t-test on continue variables, NT\$ New Taiwan Dollars, CCI Charlson comorbidity index

insomnia (307.4 and 780.5X [excluding 780.51, 780.53, and 780.57]).

\section{Kaplan-Meier model for the cumulative risk of psychiatric disorders}

The cumulative incidence of the hospitalization for an MVA injury in the OSA patients and control groups, and the differences between the two groups were significant (log-rank test, $p<0.001$, Fig. 1).

\section{Hazard ratios analysis of the hospitalization for MVA injury and mortality in OSA patients}

In this study, 172 (5.7\%, or 575.3 per 100,000 person-year) in the OSA cohort, and 358 (3.97\%, 372.0 per 100,000 person-year) suffered from hospitalization for an MVA injury in the non-OSA controls $(p<0.001$, Table 2$)$. Table 2 also shows the Cox regression analysis of the factors associated with the risk of an MVA injury. The crude HR was
2.35 (95\% CI: 1.96-2.81, $p<0.001$ ), after adjusting for age, sex, CCI scores, geographical area of residence, urbanization level of residence, and monthly income, the adjusted HR was $2.18(95 \%$ CI: $1.79-2.64, p<0.001)$. For the OSA patients with comorbidities such as insomnia, anxiety disorder, depressive disorder, bipolar disorder, psychotic disorder, alcohol-related disorders and other substance-related disorders were associated with the risk of hospitalization for MVA injury, in comparison to those without these comorbidities. The OSA patients with medications, such as hypnotic (Z-drugs and benzodiazepines) and other sedative medications such as antihistamines, antidepressants, and antipsychotics, were associated with the risk of hospitalization for an MVA injury, in comparison to those without these medications. Furthermore, the risk of MVA hospitalization would have increased $57 \%$ at every score of CCI.

In this study, $10(0.33 \%$, or 33.4 per 100,000 personyear) in the OSA cohort, and $4(0.04 \%, 4.2$ per 100,000

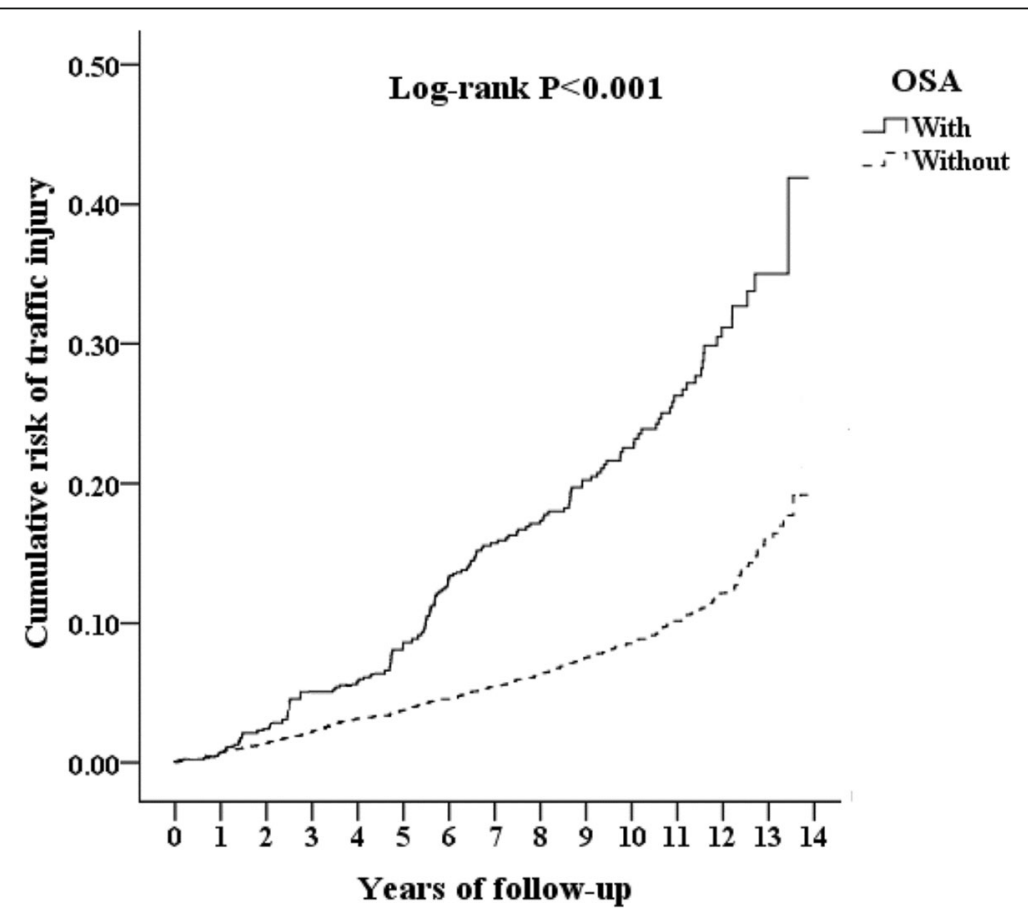

Fig. 1 Kaplan-Meier for cumulative incidence of hospitalization for the hospitalization for MVA injury among aged 20 and over stratified by OSA with log-rank test (MVA = motor vehicle accident) 
Table 2 Distribution and hazard ratio of hospitalization for motor vehicle accident injury in OSA patients

\begin{tabular}{|c|c|c|}
\hline OSA vs No OSA (N) & 3025 & 9075 \\
\hline MVA injury ${ }^{*} N(\%)$ & $172(5.7 \%)$ & $358(3.97 \%)$ \\
\hline per $10^{5}$ person-year & 575.3 & 392.0 \\
\hline Crude HR (reference: non-OSA) & 2.35 (95\% Cl: 1.96-2.81) & \\
\hline Adjusted HR (reference: non-OSA) & $2.18(95 \% \text { Cl: } 1.79-2.64)^{* * *}$ & \\
\hline Male (reference: female), adjusted HR & $1.48(95 \% \text { Cl: } 1.18-1.71)^{* * *}$ & \\
\hline $\mathrm{CCl}$, adjusted HR & $1.57(95 \% \text { Cl: } 1.55-1.59)^{* * *}$ & \\
\hline \multicolumn{3}{|l|}{ Comorbidities (reference: without), adjusted HR } \\
\hline Insomnia & $2.96(95 \% \mathrm{Cl}: 1.43-5.33)^{* * *}$ & \\
\hline Idiopathic hypersomnia & $18.22(95 \% \mathrm{Cl} 0.45-167.21)$ & \\
\hline Circadian rhythm sleep disorder, shift work type & No MVA injury events & \\
\hline Anxiety disorders & $5.11(95 \% \mathrm{Cl}: 3.98-7.66)^{* * *}$ & \\
\hline Depressive disorders & $4.35(95 \% \mathrm{Cl}: 2.06-6.53)^{* * *}$ & \\
\hline Bipolar disorders & 3.38 (95\%Cl: $2.11-4.79)^{* * *}$ & \\
\hline Psychotic disorders & $2.64(95 \% \mathrm{Cl}: 1.29-3.86)^{* * *}$ & \\
\hline Restless leg syndrome & No MVA injury events & \\
\hline Periodic limb movement disorder & No MVA injury events & \\
\hline Alcohol-related disorders & $5.71(95 \% \mathrm{Cl}: 2.63-8.82)^{* * *}$ & \\
\hline Other substance-related disorders & 3.59 (95\%Cl: $1.11-4.94)^{*}$ & \\
\hline \multicolumn{3}{|l|}{ Medications (reference: without), adjusted HR } \\
\hline Hypnotics (Z-drugs and benzodiazepine) & $2.31(95 \% \mathrm{Cl}: 1.84-2.98)^{* * *}$ & \\
\hline Antihistamines & 1.30 (95\%Cl: $1.01-1.62)^{*}$ & \\
\hline Antidepressants & $1.64(95 \% \mathrm{Cl}: 1.24-2.13)^{* *}$ & \\
\hline Antipsychotics & $1.81(95 \% \mathrm{Cl}: 1.31-2.20)^{* * *}$ & \\
\hline
\end{tabular}

OSA obstructive sleep apnea, MVA motor vehicle accidents, HR hazard ratio, CCI Charlson comorbidity index; Adjusted for the variables listed in Table 1 ${ }^{*} P<0.05,{ }^{* *} P<0.01,{ }^{* * *} P<0.001$

person-year) in the non-OSA controls, suffered from an MVA injury mortality $(p<0.05)$. The crude HR was 5.11 (95\% CI: $1.59-16.35, p<0.001$ ), after adjusting for age, sex, CCI scores, geographical area of residence, urbanization level of residence, and monthly income, the adjusted HR was 2.25 (95\% CI: $1.57-2.94, p<0.001)$. In addition, in this study, 200 (6.61\%, or 669.0 per 100,000 person-year) in the OSA cohort, and 358 (3.97\%, 790.7 per 100,000 personyear) in the non-OSA controls, suffered from the all-cause mortality $(p<0.05)$. The crude HR was 0.86 (95\% CI: 0.751.04), after adjusting for age, sex, CCI scores, geographical area of residence, urbanization level of residence, and monthly income, the adjusted HR was 1.02 (95\% CI: 0.881.59) (Additional file 3: Table S2).

\section{Subgroup analysis of with stratification by factors of comorbidities and medications and the risk of hospitalization for MVA injury}

Additional file 4: Table S3 depicts that the subgroup analysis of the stratification by factors of the comorbidities and medications and the risk of hospitalization for an MVA injury. The OSA patients, in comparison to the
non-OSA controls, were associated with the risk of hospitalization for an MVA injury, no matter with or without insomnia, anxiety disorders, depressive disorders, bipolar disorders, psychotic disorders, and other substance-related disorders.

\section{Hazard ratio analysis of the hospitalization for MVA injury in different types and severity in OSA patients}

The OSA cohort was associated with an increased risk in injury diagnosis as being fracture, dislocation, intracranial/internal injury, open wound, crushing, nerves and spinal cord injury, and other injuries, associated with injury types as drivers of motor vehicles, and other types, when compared to the control group. The OSA cohort was associated with the overall increased risk of the hospitalization for an MVA injury both in the ISS score $<$ or $\geqq 16$ (Table 3 ).

\section{Modafinil and methylphenidate and the risk of the hospitalization for MVA injury in OSA patients}

Table 4 depicts the modafinil and methylphenidate usage and the risk of hospitalization for the MVA injury of the 
Table 3 Hazard Ratios in injury diagnosis, types, and severity with significant findings, after Cox regression model analysis

\begin{tabular}{|c|c|c|c|c|c|c|c|c|c|}
\hline \multirow[t]{2}{*}{ Injury subgroup } & \multicolumn{3}{|l|}{ OSA } & \multicolumn{3}{|c|}{ No OSA } & \multirow{2}{*}{$\begin{array}{l}\text { Adjusted } \\
\text { HR }\end{array}$} & \multirow{2}{*}{$\begin{array}{l}95 \% \\
\mathrm{Cl}\end{array}$} & \multirow{2}{*}{$\begin{array}{l}95 \% \\
\mathrm{Cl}\end{array}$} \\
\hline & Event & PYS & per $10^{5} \mathrm{PYs}$ & Event & PYS & per $10^{5} \mathrm{PYS}$ & & & \\
\hline Total & 172 & $29,895.12$ & 575.34 & 358 & $96,242.00$ & 371.98 & $2.18^{* * *}$ & 1.79 & 2.64 \\
\hline \multicolumn{10}{|l|}{ Injury diagnosis } \\
\hline Fracture & 48 & $29,895.12$ & 160.56 & 163 & $96,242.00$ & 169.36 & $1.33^{*}$ & 1.15 & 1.69 \\
\hline Dislocation & 6 & $29,895.12$ & 20.07 & 8 & $96,242.00$ & 8.31 & $3.39^{* * *}$ & 2.80 & 4.12 \\
\hline Intracranial / internal injury & 30 & $29,895.12$ & 100.35 & 106 & $96,242.00$ & 110.14 & $1.28^{*}$ & 1.03 & 1.77 \\
\hline Open wound & 9 & $29,895.12$ & 30.11 & 27 & $96,242.00$ & 28.05 & $1.51^{* *}$ & 1.19 & 1.89 \\
\hline Crushing & 3 & $29,895.12$ & 10.04 & 1 & $96,242.00$ & 1.04 & $13.58^{* * *}$ & 11.27 & 16.39 \\
\hline Injury to nerves and spinal cord & 1 & $29,895.12$ & 3.35 & 2 & $96,242.00$ & 2.08 & $2.27^{* * *}$ & 1.86 & 2.78 \\
\hline Other injury & 65 & $29,895.12$ & 217.43 & 14 & $96,242.00$ & 14.55 & $21.03^{* * *}$ & 17.43 & 25.35 \\
\hline \multicolumn{10}{|l|}{ Injury types } \\
\hline Driver of motor vehicle & 5 & $29,895.12$ & 16.73 & 11 & $96,242.00$ & 11.43 & $2.07^{* * *}$ & 1.70 & 2.56 \\
\hline Others & 53 & $29,895.12$ & 177.29 & 87 & $96,242.00$ & 90.40 & $2.76^{* * *}$ & 2.25 & 3.30 \\
\hline \multicolumn{10}{|l|}{ MVA injury severity } \\
\hline ISS $<16$ & 98 & $29,895.12$ & 327.81 & 224 & $96,242.00$ & 232.75 & $1.98^{* * *}$ & 1.61 & 2.40 \\
\hline ISS $\geqq 16$ & 74 & $29,895.12$ & 247.53 & 134 & $96,242.00$ & 139.23 & $2.51^{* * *}$ & 2.02 & 3.13 \\
\hline
\end{tabular}

PYs Person-years, Adjusted HR Adjusted Hazard ratio, $\mathrm{Cl}$ confidence interval, MVA motor vehicle accidents

${ }^{*} P<0.05,{ }^{* *} P<0.01,{ }^{* * *} P<0.001$

Table 4 Factors of traffic injury by using Cox regression among OSA patients in different model

\begin{tabular}{|c|c|c|c|c|c|c|c|c|c|}
\hline & \multicolumn{3}{|l|}{ Total } & \multicolumn{3}{|l|}{ ISS $<16$} & \multicolumn{3}{|l|}{$\mathrm{ISS} \geqq 16$} \\
\hline & Adjusted HR & $95 \% \mathrm{Cl}$ & $95 \% \mathrm{Cl}$ & Adjusted HR & $95 \% \mathrm{Cl}$ & $95 \% \mathrm{Cl}$ & Adjusted HR & $95 \% \mathrm{Cl}$ & $95 \% \mathrm{Cl}$ \\
\hline Either modafinil or methylphenidate $(N=1690)$ & $0.82^{* * *}$ & 0.70 & 0.83 & $0.78^{* * *}$ & 0.68 & 0.80 & 0.89 & 0.74 & 1.02 \\
\hline PDC $1-50 \%(N=1264)$ & $0.87^{* *}$ & 0.71 & 0.88 & $0.82^{* * *}$ & 0.69 & 0.86 & 0.95 & 0.76 & 1.09 \\
\hline PDC $51-100 \%(N=426)$ & $0.78^{* * *}$ & 0.69 & 0.79 & $0.73^{* * *}$ & 0.67 & 0.76 & $0.85^{*}$ & 0.73 & 0.97 \\
\hline Modafinil $(N=933)$ & $0.83^{* * *}$ & 0.71 & 0.84 & $0.78^{* * *}$ & 0.69 & 0.82 & 0.90 & 0.76 & 1.05 \\
\hline PDC $1-50 \%(N=685)$ & $0.89^{* *}$ & 0.73 & 0.90 & $0.84^{* * *}$ & 0.71 & 0.87 & 0.97 & 0.78 & 1.11 \\
\hline PDC $51-100 \%(N=248)$ & $0.78^{* *}$ & 0.70 & 0.79 & $0.73^{* * *}$ & 0.68 & 0.77 & 0.85 & 0.73 & 1.01 \\
\hline Methylphenidate $(N=893)$ & $0.82^{* * *}$ & 0.69 & 0.92 & $0.77^{* * *}$ & 0.67 & 0.79 & 0.89 & 0.73 & 1.01 \\
\hline PDC 1-50\% $(N=680)$ & $0.85^{* * *}$ & 0.70 & 0.87 & $0.80^{* * *}$ & 0.68 & 0.85 & 0.93 & 0.73 & 1.08 \\
\hline PDC $51-100 \%(N=213)$ & $0.78^{* * *}$ & 0.69 & 0.80 & $0.73^{* * *}$ & 0.67 & 0.76 & $0.85^{*}$ & 0.72 & 0.96 \\
\hline Modafinil only $(N=797)$ & $0.88^{*}$ & 0.82 & 0.96 & $0.94^{*}$ & 0.79 & 0.93 & 0.96 & 0.86 & 1.17 \\
\hline PDC $1-50 \%(N=584)$ & 0.90 & 0.82 & 1.02 & $0.85^{*}$ & 0.80 & 0.99 & 1.00 & 0.86 & 1.24 \\
\hline PDC $51-100 \%(N=213)$ & $0.85^{*}$ & 0.81 & 0.93 & $0.80^{* *}$ & 0.78 & 0.90 & $0.93^{*}$ & 0.85 & 0.99 \\
\hline Methylphenidate only $(N=757)$ & $0.84^{*}$ & 0.78 & 0.90 & $0.77^{* * *}$ & 0.76 & 0.88 & 0.92 & 0.82 & 1.12 \\
\hline PDC $1-50 \%(N=579)$ & $0.86^{*}$ & 0.79 & 0.93 & $0.81^{* * *}$ & 0.76 & 0.89 & 0.94 & 0.83 & 1.14 \\
\hline PDC $50-100 \%(N=178)$ & $0.83^{* *}$ & 0.77 & 0.89 & $0.78^{* * *}$ & 0.74 & 0.86 & $0.90^{*}$ & 0.81 & 0.96 \\
\hline Modafinil \& Methylphenidate $(N=136)$ & $0.79^{* * *}$ & 0.64 & 0.85 & $0.74^{* * *}$ & 0.62 & 0.83 & 0.86 & 0.67 & 1.05 \\
\hline PDC $1-50 \%(N=101)$ & $0.81^{* * *}$ & 0.65 & 0.86 & $0.77^{* * *}$ & 0.63 & 0.84 & 0.88 & 0.69 & 1.06 \\
\hline PDC $50-100 \%(N=35)$ & $0.78^{* * *}$ & 0.63 & 0.79 & $0.70^{* * *}$ & 0.61 & 0.74 & $0.81^{*}$ & 0.66 & 0.94 \\
\hline
\end{tabular}

$H R$ hazard ratio, $\mathrm{Cl}$ confidence interval, Adjusted HR Adjusted variables listed in Table 1

${ }^{*} P<0.05,{ }^{* *} P<0.01,{ }^{* * *} P<0.001$ 
OSA cohort. In our study, modafinil or methylphenidate usage was associated with a nearly $20 \%$ decreased risk of the overall hospitalization for MVA injury. In general, the higher the PDC of these medications was used, the lower the risk of hospitalization for an MVA injury was found. However, for the patients of medication PDC of 51$100 \%$, the usage of these medications was not associated with a decreased risk of injury in the patients with ISS $\geqq$ 16. Neither the CPAP nor pharyngeal surgery was associated with a decreased risk of hospitalization of an MVA injury. The distributions of stimulants and theCPAP/ pharyngeal surgery among the OSA patients were shown in Additional file 5: Table S4 and Additional file 6: Table S5, respectively. The numbers of modafinil, methylphenidate, and pharyngeal surgery used in the OSA patients are as shown in the supplementary tables (Additional file 5: Table S4 and Additional file 6: Table S5). Additional file 7: Table S6 shows that both individual and joint treatment of the CPAP and stimulants were associated with a lower risk of MVA injury.

\section{Discussion}

\section{Association between OSA and the risk of the} hospitalization for MVA injury

In this study, we have examined the association between the OSA and the risk of an MVA injury. After adjusting covariates, the adjusted HR was 2.18 for the OSA cohort (95\% CI: $1.79-2.64, p<0.001)$ when compared with the control group. In other words, the OSA cohort had a 2.3fold risk of developing an MVA injury. The Kaplan-Meier analysis revealed that the study subjects had a significantly higher 15-year hospitalization for the MVA incidence than the controls ( $\log$ rank, $p<0.001)$. Furthermore, in this study, the OSA was associated with the increased risk of hospitalization for MVA injury in the severity of the ISS score $<$ or $\geqq 16$. Usage of modafinil and methylphenidate was associated with a nearly $20 \%$ decreased risk of the hospitalization for an MVA injury in the OSA cohort. This study is distinct since we found the association between OSA and the hospitalization for an MVA injury, in comparison to the one previous study about the association between OSA and the crashes from the MVA [10, 11]. To the best of our knowledge, this is the first study that depicts the decreased risk of the hospitalization for an MVA injury risk in the OSA patients with modafinil or methylphenidate usage, from a nationwide, claims database in Taiwan.

\section{Comparison of this study to previous literatures}

In comparison to previous studies on the association between OSA and MVA [13-15], this study was distinct in the following points: first, this is a cohort study from a larger nationwide database, in comparison to case control or cross-sectional studies. Second, we have examined the effects of the stimulants on the risk of the hospitalization for an MVA injury in the OSA patients. Previous studies have found that stimulants would improve the OSA patients driving performance [34, 35]. Previous articles of systematic reviews and meta-analysis have reported the association between OSA and the motor vehicle crashes, and the effects of CPAP therapy [10,36]. In our study, we found that modafinil and methylphenidate usage was associated with a lower risk of the overall hospitalization for an MVA injury, not just motor vehicle crashes. In general, the higher the PDC of these medications used, the lower the risk of hospitalization for the MVA injury was found. A larger clinical trial for the OSA patients with modafinil or methylphenidate might well be needed to confirm this association.

\section{Possible mechanisms for the increased risk of the hospitalization for MVA injury in OSA patients}

Patients with OSA, EDS, or hypersomnolence, are associated with the risk of the hospitalization for an MVA injury, since the OSA with EDS would impair the safety of driving, while the driving simulator technology declines in driving performance due to the EEG-defined microsleeps, using the driving simulated technology [37, 38]. In this study, insomnia, anxiety disorder, depressive disorder, bipolar disorder, psychotic disorder, alcohol-related disorders, other substance-related disorders, and several medications such as hypnotics, antihistamines, antidepressants, and antipsychotics, were associated with hospitalization for an MVA injury. The impact of EDS from the comorbidities and concomitant medications needed to be warranted. The idiopathic hypersomnia was not associated with the risk of hospitalization for the MVA injury.

The OSA could also impair the cognitive performance in attention, memory, and fronto-executive functioning $[39,40]$, and this could also contribute to the risk-proneness in the OSA patients. Previous studies have reported that the usage of stimulants could improve wakefulness and cognitive performance in the OSA patients [41, 42], and our study also concords with these findings by showing a lower risk of the hospitalization for an MVA injury in the OSA patients who received modafinil or methylphenidate.

\section{CPAP and pharyngeal surgery and the risk of the hospitalization for MVA injury in OSA patients}

As the CPAP treatment is not reimbursed by the NHI policy, we therefore could only use indirect methods to confirm the usage of the CPAP treatment as aforementioned. The lower usage of CPAP might be related to the findings that the acceptance of CPAP is low in Taiwan [43, 44]. The usage of oral appliances, such as the mandibular advancement devices, is not reimbursed by the NHI, therefore, we could not evaluate the effects 
of these appliances on the hospitalization for an MVA injury in the OSA cohort.

\section{Strengths of this study}

The present study has several strengths: First, we used the NHIRD with a large sample size in this study, and, as aforementioned, in one recent study, the accuracy of diagnosis of OSA recorded in the NHIRD, has been validated as 99\% [26]. Second, a 1:3 sex-, age-, index date-matched comparator group was enrolled in this study. Third, we have assessed as to whether the usage of modafinil or methylphenidate alters the risk of hospitalization for an MVA injury in OSA. Fourth, we excluded patients who were comorbid with narcolepsy, and thus, we could evaluate the effects of modafinil or methylphenidate only for the OSA patients.

\section{Limitations of this study}

The present study has several limitations that warrant consideration. First, similar to previous studies using the NHIRD on the OSA as aforementioned, not all of the data were recorded in the NHIRD, and we were unable to evaluate the severity, weakness severity, laboratory parameters, or lung function examinations in the apnea patients. However, one recent study has validated that the accuracy of diagnosis of the OSA recorded in the NHIRD was 99\%, as aforementioned [26]. Second, other factors, such as the body mass index, genetic, psychosocial, environmental factors, and lifestyle, were not included in the dataset. For example, we have analyzed the circadian rhythm sleep disorder, shift work type instead of the lifestyle as shift work. Third, the lack of data on the severity of the OSA would limit the generalization of the results of this study. Although the diagnosis of the OSA requires overnight PSG to detect the frequency of apneic and hypopneic events $[45,46]$. the NHIRD does not contain the records of overnight oximetry screening prior to deciding about PSG, which may produce a $17 \%$ false negative rate [47]. Fourth, the NHI program started in 1995, but in this study, the NHIRD we used, contained only a database of 15 years. We would like to highly recommend that a longer follow-up study is needed in the future. Fifth, there were no direct records of the CPAP in the NHIRD, the usage of CPAP therapy is crudely based on whether an additional PSG was requested, within the first 6 months after the OSA diagnosis, However, one study about the acceptance and adherence for the CPAP found that the continuous (nightly) use of the CPAP was around 66.7-74.3\%, which were higher than the discontinuous (irregular) users, or, in the OSA patients who were prescribed this treatment [48]. Sixth, psychostimulants for other sleep problems such as narcolepsy and EDS might well be associated with the decreased risk of hospitalization for
MVA injury, however, we have excluded the diagnosis of narcolepsy from the enrollees. Seventh, the usage of some substances such as alcohol, marijuana and cocaine were associated with EDS [49], and thus could be associated with the risk of hospitalization for an MVA injury, however, the records of usage of alcohol, marijuana, cocaine or other psychoactive substances were not included in the NHIRD. We therefore analyzed the alcohol- or other substance-related disorders in the present study and found that these disorders were associated the increased risk of hospitalization for an MVA injury, in comparison to those without these comorbidities. Finally, in such a claims database study, the records might not contain all the records. In addition, these records might not reflect the fact that many different healthcare professionals have been involved in patient care, so the measurement of risk factors and outcomes throughout the database would probably be less accurate and consistent than that achieved with a prospective cohort study design.

\section{Conclusion}

This study found a nearly 2.2-fold higher risk of hospitalization for an MVA injury in the untreated OSA patients. Furthermore, modafinil and methylphenidate usage was associated with a nearly $20 \%$ decreased risk of the overall hospitalization for an MVA injury in patients with OSA. These findings strongly suggest that clinicians should now provide a careful follow-up and medical treatment for these patients.

\section{Supplementary information}

Supplementary information accompanies this paper at https://doi.org/10. 1186/s12890-019-1041-1.

Additional file 1: Figure S1. The flowchart of study sample selection from National Health Insurance Research Database in Taiwan.

Additional file 2: Table S1. Diagnosis and weights in the Charlson Comorbidity Index.

Additional file 3: Table S2. Distribution and hazard ratio of mortality for motor vehicle accident injury and all-cause mortality in OSA patients.

Additional file 4: Table S3. Subgroup analysis of with stratification by factors of comorbidities and medications and the risk of hospitalization for MVA injury.

Additional file 5: Table S4. Distribution of medication among OSA patients.

Additional file 6: Table S5. Distribution of Treatment surgery.

Additional file 7: Table S6. Factors of traffic injury by using Cox regression among OSA patients in different treatments.

\section{Abbreviations}

CCl: Charlson Comorbidity Index; Cl: Confidence interval; CPAP: Continuous positive airway pressure; EDS: Excessive daytime sleepiness; HR: Hazard ratio; ICD-9-CM: International Classification of Diseases, 9th Revision, Clinical Modification; ISS: Injury Severity Score; LHID: Longitudinal Health Insurance Database; MVA: Motor vehicle accident; NHI: National Health Insurance; NHIRD: National Health Insurance Research Database; NT\$: New Taiwan Dollars; OSA: Obstructive sleep apnea; PDC: Proportion of days covered; PSG: Polysomnography 


\section{Acknowledgements}

Authors appreciate Ms. Hui-Wen Yeh for her help in proof reading.

\section{Authors' contributions}

Y-CL, T-YC, and C-SL conceived and designed the study. W-CC and N-ST collected data for the study. C-HC, W-CC, C-SL and N-ST analyzed the data. H-AC, Y-CK, C-ST, and N-ST interpreted data. N-ST and C-SL critically revised the manuscript. All the authors collected and interpreted data and wrote and approved the paper.

\section{Funding}

This work was supported by the Medical Affairs Bureau, the Ministry of Defense of Taiwan (MAB-107-084), and the Tri-Service General Hospital Research Foundation (TSGH-C106-106, TSGH-C107-004, TSGH-C107-106, TSGH-C108-003, TSGH-C108-027, and TSGH-C108-151). However, all authors declare no financial interests nor conflict of interest or the appearance of a conflict of interest with regard to the work

\section{Availability of data and materials}

Data are available from the National Health Insurance Research Database (NHIRD) published by Taiwan National Health Insurance (NHI) Bureau. Due to legal restrictions imposed by the government of Taiwan in relation to the "Personal Information Protection Act", data cannot be made publicly available. Requests for data can be sent as a formal proposal to the NHIRD (http://nhird.nhri.org.tw).

\section{Ethics approval and consent to participate}

Since the identifiable database of individuals included in the NHIRD were all encrypted in order to protect individual privacy, the NHI Administration has given general approval for their data to be used in this research. Because the NHIRD has the advantage of providing a large-scale, longitudinal, reliable dataset, leading to extensive use for population-based researches in Taiwan, the Institutional Review Board of Tri-Service General Hospital was aware of this and approved the research to proceed, and also agreed that the benefit justified waiving the need for individual written informed consent in such a study. (IRB No. 1-106-05-169).

\section{Consent for publication}

Not Applicable

\section{Competing interests}

The authors declare that they have no competing interests.

\section{Author details}

${ }^{1}$ Division of Cardiovascular Surgery, Department of Surgery, Tri-Service General Hospital, National Defense Medical Center, Taipei, Taiwan. ${ }^{2}$ Department of Biological Science and Technology, National Chiao Tung University, No.75, Po-Ai Street, Hsinchu 30068, Taiwan. ${ }^{3}$ Department of Psychiatry, Tri-Service General Hospital, School of Medicine, National Defense Medical Center, No. 325, Section 2, Cheng-Kung Road, Neihu District, Taipei City 11490, Taiwan. ${ }^{4}$ Department of Psychiatry, Tri-Service General Hospital, Keelung Branch, National Defense Medical Center, Taipei, Taiwan. ${ }^{5}$ Department of Medical Research, Tri-Service General Hospital, National Defense Medical Center, Taipei, Taiwan. ${ }^{6}$ School of Public Health, National Defense Medical Center, Taipei, Taiwan. ${ }^{7}$ Graduate Institute of Life Sciences, National Defense Medical Center, Taipei, Taiwan. ${ }^{8}$ Taiwanese Injury Prevention and Safety Promotion Association, Taipei, Taiwan. ${ }^{9}$ Student Counseling Center, National Defense Medical Center, Taipei, Taiwan.

${ }^{10}$ Department of Psychiatry, Tri-Service General Hospital, Song-Shan Branch, National Defense Medical Center, Taipei, Taiwan.

\section{Received: 11 February 2019 Accepted: 24 December 2019}

\section{Published online: 03 February 2020}

\section{References}

1. Malhotra A, White DP. Obstructive sleep apnoea. Lancet (London, England). 2002;360(9328):237-45.

2. Ferini-Strambi L, Fantini ML, Castronovo C. Epidemiology of obstructive sleep apnea syndrome. Minerva Med. 2004;95(3):187-202.

3. Punjabi NM. The epidemiology of adult obstructive sleep apnea. Proc Am Thorac Soc. 2008;5(2):136-43.
4. Hirsch Allen AJM, Bansback N, Ayas NT. The effect of OSA on work disability and work-related injuries. Chest. 2015;147(5):1422-8.

5. Jiang B, Liang S, Peng ZR, Cong H, Levy M, Cheng Q, Wang T, Remais JV. Transport and public health in China: the road to a healthy future. Lancet (London, England). 2017;390(10104):1781-91.

6. Vecino-Ortiz Al, Jafri A, Hyder AA. Effective interventions for unintentional injuries: a systematic review and mortality impact assessment among the poorest billion. Lancet Glob Health. 2018;6(5):e523-34.

7. Gupta R, Pandi-Perumal SR, Almeneessier AS, BaHammam AS. Hypersomnolence and traffic safety. Sleep Med Clin. 2017;12(3):489-99.

8. Powell NB, Schechtman KB, Riley RW, Guilleminault C, Chiang RP, Weaver EM. Sleepy driver near-misses may predict accident risks. Sleep. 2007;30(3):331-42.

9. Quera Salva MA, Barbot F, Hartley S, Sauvagnac R, Vaugier I, Lofaso F, Philip $P$. Sleep disorders, sleepiness, and near-miss accidents among long-distance highway drivers in the summertime. Sleep Med. 2014;15(1):23-6.

10. Tregear S, Reston J, Schoelles K, Phillips B. Obstructive sleep apnea and risk of motor vehicle crash: systematic review and meta-analysis. J Clin Sleep Med. 2009:5(6):573-81.

11. Amra B, Dorali R, Mortazavi S, Golshan M, Farajzadegan Z, Fietze I, Penzel T. Sleep apnea symptoms and accident risk factors in Persian commercial vehicle drivers. Sleep Breathing = Schlaf Atmung. 2012;16(1):187-91.

12. Sassani A, Findley L, Kryger M, Goldlust E, George C, Davidson TM. Reducing motor-vehicle collisions, costs, and fatalities by treating obstructive sleep apnea syndrome. Sleep. 2004;27(3):453-8.

13. Garbarino S, Durando P, Guglielmi O, Dini G, Bersi F, Fornarino S, Toletone A, Chiorri C, Magnavita N. Sleep Apnea, Sleep Debt and Daytime Sleepiness Are Independently Associated with Road Accidents. A Cross-Sectional Study on Truck Drivers. PloS one. 2016;11(11):e0166262.

14. Garbarino S, Pitidis A, Giustini M, Taggi F, Sanna A. Motor vehicle accidents and obstructive sleep apnea syndrome: a methodology to calculate the related burden of injuries. Chron Respir Dis. 2015;12(4):320-8.

15. Karimi M, Hedner J, Habel H, Nerman O, Grote L. Sleep apnea-related risk of motor vehicle accidents is reduced by continuous positive airway pressure: Swedish traffic accident registry data. Sleep. 2015;38(3):341-9.

16. Ho Chan W. Taiwan's healthcare report 2010. EPMA J. 2010;1(4):563-85.

17. Needham DM, Scales DC, Laupacis A, Pronovost PJ. A systematic review of the Charlson comorbidity index using Canadian administrative databases: a perspective on risk adjustment in critical care research. J Crit Care. 2005; 20(1):12-9.

18. Chinese Hospital Association. ICD-9-CM English-Chinese dictionary. Taipei: Chinese Hospital Association Press; 2000.

19. Huang HL, Ho SY, Li CH, Chu FY, Ciou LP, Lee HC, Chen WL, Tzeng NS Bronchial asthma is associated with increased risk of chronic kidney disease BMC Pulm Med. 2014;14:80.

20. Tang YJ, Ho SY, Chu FY, Chen HA, Yin YJ, Lee HC, Chu WC, Yeh HW, Chiang WS, Yeh $\mathrm{CL}$, et al. Is Zolpidem associated with increased risk of fractures in the elderly with sleep disorders? A Nationwide case cross-over study in Taiwan. PLoS One. 2015;10(12):e0146030.

21. Tzeng NS, Chang HA, Chung CH, Kao YC, Chang CC, Yeh HW, Chiang WS, Chou YC, Chang SY, Chien WC. Increased risk of psychiatric disorders in allergic diseases: a nationwide, population-based, cohort study. Front Psychiatry. 2018;9:133.

22. Tzeng NS, Chung CH, Chang HA, Chang CC, Lu RB, Yeh HW, Chiang WS, Kao YC, Chang SY, Chien WC. Obstructive sleep apnea in children and adolescents and the risk of major adverse cardiovascular events-A nationwide cohort study in Taiwan. J Clin Sleep Med. 2019;15(2):275-83.

23. Tzeng NS, Chung CH, Chang SY, Yeh CB, Lu RB, Chang HA, Kao YC, Chou YC, Yeh HW, Chien WC. Risk of psychiatric disorders in pulmonary embolism: a nationwide cohort study. J Invest Med. 2019;67(6):977-86.

24. Tseng WS, Chien WC, Chung CH, Chou YC, Tzeng NS. Risk of sleep disorders in patients with decompression sickness: a nationwide, population-based study in Taiwan. Psychiatr Danub. 2019;31(2):172-81.

25. American Academy of Sleep Medicine Task Force. Sleep-related breathing disorders in adults: recommendations for syndrome definition and measurement techniques in clinical research. The Report of an American Academy of Sleep Medicine Task Force. Sleep. 1999;22(5):667-89.

26. Su VY, Liu CJ, Wang HK, Wu LA, Chang SC, Perng DW, Su WJ, Chen YM, Lin EY, Chen TJ, et al. Sleep apnea and risk of pneumonia: a nationwide population-based study. CMAJ. 2014;186(6):415-21. 
27. Premium Contribution: How Premiums Are Calculated [www.nhi.gov.tw/ english/Content_List.aspx?n=B9C9C690524F2543\&topn=46FA76EB55BC2CB8]

28. Hang LW, Chen CF, Wang CB, Wu TN, Liang WM, Chou TC. The association between continuous positive airway pressure therapy and liver disease development in obstructive sleep apnea/hypopnea syndrome patients: a nationwide population-based cohort study in Taiwan. Sleep Breathing = Schlaf Atmung. 2017;21(2):461-7.

29. Huang WF, Lai IC. Patterns of sleep-related medications prescribed to elderly outpatients with insomnia in Taiwan. Drugs Aging. 2005;22(11):957-65.

30. Willison HJ, Jacobs BC, van Doorn PA. Guillain-Barre syndrome: surveillance and cost of treatment strategies - Authors' reply. Lancet (London, England). 2017;389(10066):253-4

31. Group SG-BST. Randomised trial of plasma exchange, intravenous immunoglobulin, and combined treatments in Guillain-Barre syndrome. Plasma Exchange. Lancet (London, England). 1997;349(9047):225-30.

32. Wong AHY, Umapathi T, Shahrizaila N, Chan YC, Kokubun N, Fong MK, Chu YP, Lau PK, Yuki N. The value of comparing mortality of Guillain-Barré syndrome across different regions. J Neurol Sci. 2014;344(1-2):60-2.

33. Baker SP, O'Neill B, Haddon W Jr, Long WB. The injury severity score: a method for describing patients with multiple injuries and evaluating emergency care. J Trauma. 1974;14(3):187-96.

34. Chapman JL, Kempler L, Chang CL, Williams SC, Sivam S, Wong KK, Yee BJ, Grunstein RR, Marshall NS. Modafinil improves daytime sleepiness in patients with mild to moderate obstructive sleep apnoea not using standard treatments: a randomised placebo-controlled crossover trial. Thorax. 2014;69(3):274-9.

35. Wang D, Bai XX, Williams SC, Hua SC, Kim JW, Marshall NS, D'Rozario A, Grunstein RR. Modafinil increases awake EEG activation and improves performance in obstructive sleep apnea during continuous positive airway pressure withdrawal. Sleep. 2015;38(8):1297-303.

36. Tregear S, Reston J, Schoelles K, Phillips B. Continuous positive airway pressure reduces risk of motor vehicle crash among drivers with obstructive sleep apnea: systematic review and meta-analysis. Sleep. 2010;33(10):1373-80.

37. Tippin J. Driving impairment in patients with obstructive sleep apnea syndrome. Am J Electroneurodiagnostic Technol. 2007;47(2):114-26.

38. Vorona RD, Ware JC. Sleep disordered breathing and driving risk. Curr Opin Pulm Med. 2002;8(6):506-10.

39. Bawden FC, Oliveira CA, Caramelli P. Impact of obstructive sleep apnea on cognitive performance. Arq Neuropsiquiatr. 2011;69(4):585-9.

40. Kim H, Thomas RJ, Yun CH, Au R, Lee SK, Lee S, Shin C. Association of Mild Obstructive Sleep Apnea With Cognitive Performance, Excessive Daytime Sleepiness, and Quality of Life in the General Population: The Korean Genome and Epidemiology Study (KoGES). Sleep. 2017;40(5):zsx012. https:// doi.org/10.1093/sleep/zsx012.

41. Hirshkowitz M, Black JE, Wesnes K, Niebler G, Arora S, Roth T. Adjunct armodafinil improves wakefulness and memory in obstructive sleep apnea/ hypopnea syndrome. Respir Med. 2007;101(3):616-27.

42. Roth T, Rippon GA, Arora S. Armodafinil improves wakefulness and longterm episodic memory in nCPAP-adherent patients with excessive sleepiness associated with obstructive sleep apnea. Sleep Breathing = Schlaf Atmung. 2008;12(1):53-62.

43. Huang YC, Lin CY, Lan CC, Wu YK, Lim CS, Huang CY, Huang HL, Yeh KH, Liu YC, Yang MC. Comparison of cardiovascular co-morbidities and CPAP use in patients with positional and non-positional mild obstructive sleep apnea. BMC Pulm Med. 2014;14:153

44. Yang MC, Huang YC, Lan CC, Wu YK, Huang KF. Beneficial effects of Longterm CPAP treatment on sleep quality and blood pressure in adherent subjects with obstructive sleep apnea. Respir Care. 2015;60(12):1810-8.

45. The Report of an American Academy of Sleep Medicine Task Force. Sleeprelated breathing disorders in adults: recommendations for syndrome definition and measurement techniques in clinical research. Sleep. 1999; 22(5):667-89.

46. Park JG, Ramar K, Olson EJ. Updates on definition, consequences, and management of obstructive sleep apnea. Mayo Clin Proc. 2011;86(6):549-54 quiz 554-545.

47. Zeidler MR, Santiago V, Dzierzewski JM, Mitchell MN, Santiago S, Martin JL. Predictors of obstructive sleep apnea on Polysomnography after a technically inadequate or Normal home sleep test. J Clin Sleep Med. 2015; 11(11):1313-8.
48. Yang MC, Lin CY, Lan CC, Huang CY, Huang YC, Lim CS, Liu YC, Wu YK. Factors affecting CPAP acceptance in elderly patients with obstructive sleep apnea in Taiwan. Respir Care. 2013;58(9):1504-13.

49. Mahoney JJ 3rd, De La Garza R 2nd, Jackson BJ, Verrico CD, Ho A, lqbal T, Newton TF. The relationship between sleep and drug use characteristics in participants with cocaine or methamphetamine use disorders. Psychiatry Res. 2014;219(2):367-71.

\section{Publisher's Note}

Springer Nature remains neutral with regard to jurisdictional claims in published maps and institutional affiliations.

\section{Ready to submit your research? Choose BMC and benefit from:}

- fast, convenient online submission

- thorough peer review by experienced researchers in your field

- rapid publication on acceptance

- support for research data, including large and complex data types

- gold Open Access which fosters wider collaboration and increased citations

- maximum visibility for your research: over $100 \mathrm{M}$ website views per year

At BMC, research is always in progress.

Learn more biomedcentral.com/submissions 